\title{
Summertime elemental mercury exchange of temperate grasslands on an ecosystem-scale
}

\author{
J. Fritsche ${ }^{1}$, G. Wohlfahrt ${ }^{2}$, C. Ammann ${ }^{3}$, M. Zeeman ${ }^{4}$, A. Hammerle ${ }^{2}$, D. Obrist ${ }^{5}$, and C. Alewell ${ }^{1}$ \\ ${ }^{1}$ Institute of Environmental Geosciences, University of Basel, Bernoullistrasse 30, 4056 Basel, Switzerland \\ ${ }^{2}$ Institute of Ecology, University of Innsbruck, Sternwartestrasse 15, 6020 Innsbruck, Austria \\ ${ }^{3}$ Agroscope Reckenholz-Taenikon Research Station ART, Air pollution/Climate group, Reckenholzstrasse 191, \\ 8046 Zurich, Switzerland \\ ${ }^{4}$ Institute of Plant Science, ETH Zurich, Universitaetsstrasse 2, 8092 Zurich, Switzerland \\ ${ }^{5}$ Desert Research Institute, Division of Atmospheric Sciences, 2215 Raggio Parkway, Reno, NV 89512, USA
}

Received: 1 October 2007 - Published in Atmos. Chem. Phys. Discuss.: 4 February 2008

Revised: 23 July 2008 - Accepted: 21 November 2008 - Published: 22 December 2008

\begin{abstract}
In order to estimate the air-surface mercury exchange of grasslands in temperate climate regions, fluxes of gaseous elemental mercury (GEM) were measured at two sites in Switzerland and one in Austria during summer 2006. Two classic micrometeorological methods (aerodynamic and modified Bowen ratio) have been applied to estimate net GEM exchange rates and to determine the response of the GEM flux to changes in environmental conditions (e.g. heavy rain, summer ozone) on an ecosystem-scale. Both methods proved to be appropriate to estimate fluxes on time scales of a few hours and longer. Average dry deposition rates up to $4.3 \mathrm{ng} \mathrm{m}^{-2} \mathrm{~h}^{-1}$ and mean deposition velocities up to $0.10 \mathrm{~cm} \mathrm{~s}^{-1}$ were measured, which indicates that during the active vegetation period temperate grasslands are a small net sink for atmospheric mercury. With increasing ozone concentrations depletion of GEM was observed, but could not be quantified from the flux signal. Night-time deposition fluxes of GEM were measured and seem to be the result of mercury co-deposition with condensing water. Effects of grass cuts could also be observed, but were of minor magnitude.
\end{abstract}

\section{Introduction}

The continued use of mercury in a wide range of products and processes and its release into the environment lead to deposition of mercury in ecosystems yet unspoiled. Its long atmospheric lifetime of about 1 to 2 years (Lin and Pehkonen,

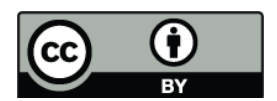

Correspondence to: J. Fritsche (johannes.fritsche@unibas.ch)
1999) enables elemental mercury $\left(\mathrm{Hg}^{0}\right)$ to migrate to remote areas far away from its emission source, and once deposited to terrestrial or aquatic surfaces it is exposed to the formation of even more toxic methylmercury (IOMC, 2002). A suite of factors determines the ultimate fate of elemental mercury and its eventual immobilisation at the Earth's surface. Depending on atmospheric chemistry, meteorological conditions and physicochemical properties of the soils mercury may be cycled fairly rapidly between terrestrial surfaces and the atmosphere (Gustin and Lindberg, 2005). However, it remains unclear whether deposited mercury is retained in background soils or whether terrestrial surfaces are even a net source of mercury (Pirrone and Mahaffey, 2005). Once deposited, mercury may be sequestered (e.g. adsorbed to soil organic matter and clay minerals), removed from the soil by leaching and erosion or re-emitted (Gustin and Lindberg, 2005). Mercury sequestered by terrestrial ecosystems might eventually be disconnected temporarily from the atmosphere-biosphere cycle, which would lead to a decrease in the pool of atmospheric mercury.

The function of vegetation in the mercury exchange with the atmosphere remains unclear. Mercury may be taken up by leaves or transferred from the soil through the plant to the atmosphere (Gustin and Lindberg, 2005; Millhollen et al., 2006). Foliar uptake has been suggested to be an important pathway for atmospheric mercury to enter terrestrial ecosystems and may represent a significant, but poorly quantified sink within the biogeochemical cycle, possibly accounting for over 1000 tons of mercury per year (Obrist, 2007). Du and Fang (1982) measured $\mathrm{Hg}^{0}$ uptake of several C3 and $\mathrm{C} 4$ plant species and demonstrated that stomatal and biochemical processes control the uptake. Atmospheric mercury

Published by Copernicus Publications on behalf of the European Geosciences Union. 
concentration was found to be the dominant factor associated with foliar mercury concentrations in different forb species (Fay and Gustin, 2007), and the successful application of different grass species in biomonitoring studies (De Temmerman et al., 2007) suggest that mercury uptake by plants is indeed of significance.

With innovations in sensitive measurement techniques in the last decade it is now possible to measure atmospheric mercury background concentrations currently ranging from 1.32 to $1.83 \mathrm{ng} \mathrm{m}^{-3}$ (Valente et al., 2007). Such instruments also allow the estimation of air-surface exchange fluxes of gaseous elemental mercury (GEM) by applying micrometeorological methods. They are based on vertical concentration profiles and permit spatially averaged measurements without disturbing ambient conditions - an essential element of longterm studies.

During our previous work on GEM exchange of a montane grassland in Switzerland we determined mean deposition rates of $5.6 \mathrm{ng} \mathrm{m}^{-2} \mathrm{~h}^{-1}$ during the vegetation period (Fritsche et al., 2008). For that study GEM concentrations were measured for a whole year in order to describe the seasonal variation of the GEM exchange. In the current study that work is extended to another montane and one lowland grassland site along the Alps with the aim to determine whether temperate grasslands in general are net sinks for atmospheric mercury or whether GEM exchange is site specific. Two classical micrometeorological methods are applied to estimate the GEM fluxes: the aerodynamic method and the modified Bowen ratio (MBR) method. By performing measurements during the vegetation period, we test the potential and limitations of these two methods and also attempt to capture changes in the GEM flux caused by alteration of environmental conditions, e.g. grass cuts, heavy precipitation, and elevated summer ozone concentrations.

\section{Experimental}

\subsection{Site description}

For our GEM flux measurements we selected three grassland sites in Switzerland and Austria with existing micrometeorological towers. The first site, Fruebuel, is located on an undulating plateau $1000 \mathrm{~m}$ a.s.l. in central Switzerland. It is intensively used for cattle grazing and is bordered by forest, wetlands and other grasslands. The second location, Neustift, is an intensively managed, flat grassland in the Austrian Stubai Valley at an elevation of $970 \mathrm{~m}$ a.s.l. This previously alluvial land lies between the Ruetz river and pastures and is primarily used for hay production. The third site is situated in Oensingen on the Swiss central plateau (Mittelland) at $450 \mathrm{~m}$ a.s.l. between the Jura and the western Alps. It serves as an experimental farmland with extensive management and neighbours agricultural land that borders on a motorway in the north-west.
All three sites are equipped with eddy covariance (EC) flux towers. The stations in Neustift and Oensingen are affiliated with the CarboEurope $\mathrm{CO}_{2}$ flux network and are operated by the Institute of Ecology, University of Innsbruck, Austria and the Federal Research Station Agroscope ART, Switzerland, respectively. At Fruebuel the EC flux tower is operated by the Institute of Plant Science, ETH Zurich to investigate greenhouse gas fluxes from agricultural land in the context of a changing climate.

Details about the meteorological and pedological conditions of all three sites are listed in Table 1. The predominant wind direction at Fruebuel is SW to SSW, showing a distinct channelled flow as a result of the local, undulating, sub-alpine topography. The footprint of the EC flux measurements has been determined by using the footprint model of Kljun et al. (2004). For the EC sensor height of $2.55 \mathrm{~m}$ this resulted in a footprint coverage of $>80 \%$ within a radius of $60 \mathrm{~m}$. Within approximately $200 \mathrm{~m}$ of the predominant wind direction vegetation is homogenous and the calculated footprint area covers the intensively managed part of the grassland. Neustift on the other hand represents a site with the characteristic wind regime of an Alpine valley - the wind blowing into the valley from NE during the day and blowing out of the valley from SW during the night. Vegetation is uniform for around 300 and $900 \mathrm{~m}$ in the directions of the dayand night-time winds, respectively, with the footprint maximum lying within these boundaries for more than $90 \%$ of all cases. In Oensingen the fetch length is about $70 \mathrm{~m}$ along the dominant wind sectors (SW and NE) and $26 \mathrm{~m}$ in the perpendicular axis. Using the footprint model of Kormann and Meixner (2001) the fraction of the field contributing to the measured $\mathrm{EC} \mathrm{CO}_{2}$ flux is $>70 \%$ during most of the daytime, whereas during night-times, this fraction is generally lower and highly variable due to very stable conditions. It has to be noted, that the fetch length is smaller than the heights of the GEM gradient measurements would require (see Sect. 2.4). However, for the benefit of higher vertical gradients on a well characterised grassland site this inadequacy was accepted.

The gleyic cambisols at Fruebuel and the stagnic cambisols at Oensingen are rather deep $(>1 \mathrm{~m})$, while the gleyic fluvisol in Neustift is very shallow $(<30 \mathrm{~cm})$. Total mercury concentrations at all sites are representative of uncontaminated background soils (see Table 1), although the $\mathrm{Hg}_{\text {tot }}$ concentration at Fruebuel lies at the threshold value of $100 \mathrm{ng} \mathrm{g}^{-1}$.

\subsection{Micrometeorological methods}

A variety of micrometeorological techniques to estimate atmosphere-surface exchange fluxes of trace gases have been developed (Dabberdt et al., 1993; Lenschow, 1995; Baldocchi, 2006; Foken, 2006). Of these, the eddy covariance approach would be most straightforward, but is currently not feasible for GEM as no fast-response sensor is yet available (Dabberdt et al., 1993; Lindberg et al., 1995). We 
Table 1. Summary of site specifications, environmental conditions as well as atmospheric GEM and $\mathrm{CO}_{2}$ data.

\begin{tabular}{|c|c|c|c|c|}
\hline Variable & Unit & Fruebuel & Neustift & Oensingen \\
\hline \multicolumn{5}{|l|}{ Site } \\
\hline Location & {$[-]$} & $\begin{array}{r}47^{\circ} 6^{\prime} 47^{\prime \prime} \mathrm{N} \\
8^{\circ} 32^{\prime} 16^{\prime \prime} \mathrm{E}\end{array}$ & $\begin{array}{l}47^{\circ} 07^{\prime} 00^{\prime \prime} \mathrm{N} \\
11^{\circ} 19^{\prime} 07^{\prime \prime} \mathrm{E}\end{array}$ & $\begin{array}{l}47^{\circ} 17^{\prime} 8.3^{\prime \prime} \mathrm{N} \\
7^{\circ} 43^{\prime} 55.7^{\prime \prime} \mathrm{E}\end{array}$ \\
\hline Measurement period & {$[-]$} & 06.07.06-20.07.06 & 14.06.06-29.06.2006 & 14.09.06-26.09.06 \\
\hline Elevation & {$[\mathrm{m}]$} & 1000 & 970 & 450 \\
\hline Mean annual temperature & {$\left[{ }^{\circ} \mathrm{C}\right]$} & 7.0 & 6.3 & 9.5 \\
\hline Mean annual precipitation & {$[\mathrm{mm}]$} & 1200 & 850 & 1100 \\
\hline \multicolumn{5}{|l|}{ Soil specifications } \\
\hline Type & {$[-]$} & gleyic cambisol & gleyic fluvisol & stagnic cambisol \\
\hline Bulk density (A-horizon) & {$\left[\mathrm{g} \mathrm{cm}^{-3}\right]$} & 1.50 & 1.03 & 1.2 \\
\hline $\mathrm{C}_{\text {org }}(\mathrm{A}$-horizon $)$ & {$\left[\mathrm{mgg} \mathrm{g}^{-1}\right]$} & 18 & 28 & 28 \\
\hline pH (A-horizon) & {$[-]$} & 4.5 & 6.1 & 5.3 \\
\hline $\mathrm{Hg}_{\text {tot }}$ concentration & {$\left[\mathrm{ng} \mathrm{g}^{-1}\right]$} & 100.8 & 43.9 & 71.2 \\
\hline \multicolumn{5}{|l|}{$\begin{array}{l}\text { Micrometeorological conditions } \\
\text { during measurements }\end{array}$} \\
\hline Air temperature, mean & {$\left[{ }^{\circ} \mathrm{C}\right]$} & 18.5 & 20.7 & 15.8 \\
\hline $\mathrm{PAR}$, mean & {$\left[\mu \mathrm{mol} \mathrm{m}^{-2} \mathrm{~s}^{-1}\right]$} & 560 & 550 & 310 \\
\hline Relative humidity, mean & $\%$ & 75.9 & 69.7 & 95.6 \\
\hline $\mathrm{u}^{*}$, mean & {$\left[\mathrm{m} \mathrm{s}^{-1}\right]$} & 0.17 & 0.17 & 0.12 \\
\hline Water vapour flux, mean & {$\left[\mathrm{mmol}^{-2} \mathrm{~s}^{-1}\right]$} & 2.7 & 2.0 & 1.7 \\
\hline Precipitation, total & {$[\mathrm{mm}]$} & 26 & 0 & 90 \\
\hline Soil water content, mean & {$\left[\mathrm{m}^{3} \mathrm{~m}^{-3}\right]$} & 0.32 & 0.22 & 0.44 \\
\hline \multicolumn{5}{|c|}{$\begin{array}{l}\text { Data coverage of GEM fluxes determined } \\
\text { by aerodaynmic/MBR methods }\end{array}$} \\
\hline Measurement coverage & $\%$ & $84 / 84$ & $85 / 73$ & $68 / 40$ \\
\hline Flux data coverage & $\%$ & $58 / 58$ & $44 / 44$ & $27 / 27$ \\
\hline \multicolumn{5}{|l|}{ Atmospheric GEM } \\
\hline GEM concentration, mean & {$\left[\mathrm{ng} \mathrm{m}^{-3}\right]$} & $1.20(0.76 \text { to } 1.61)^{\mathrm{c}}$ & $1.22(0.48 \text { to } 1.70)^{\mathrm{c}}$ & $1.66(0.94 \text { to } 4.71)^{\mathrm{c}}$ \\
\hline GEM gradient $^{\mathrm{a}}$, day, mean ${ }^{\mathrm{a}}$ & {$\left[\mathrm{ng} \mathrm{m}^{-4}\right]$} & $0.02(-0.04 \text { to } 0.13)^{\mathrm{c}}$ & $<0.02(-0.06 \text { to } 0.07)^{\mathrm{c}}$ & $<0.02(-0.32 \text { to } 0.16)^{\mathrm{c}}$ \\
\hline GEM gradient ${ }^{\mathrm{a}}$, night, mean & {$\left[\mathrm{ng} \mathrm{m}^{-4}\right]$} & $0.06(-0.03 \text { to } 0.27)^{\mathrm{c}}$ & $0.02(-0.06 \text { to } 0.17)^{\mathrm{c}}$ & $-0.04(-0.40 \text { to } 0.11)^{\mathrm{c}}$ \\
\hline GEM flux, MBR, mean & {$\left[\mathrm{ng} \mathrm{m}^{-2} \mathrm{~h}^{-1}\right]$} & $-1.6(-14 \text { to } 14)^{\mathrm{c}}$ & $-0.5^{\mathrm{b}}(-76 \text { to } 37)^{\mathrm{c}}$ & $0.3^{\mathrm{b}}(-18 \text { to } 30)^{\mathrm{c}}$ \\
\hline GEM flux, aerodynamic, mean & {$\left[\mathrm{ng} \mathrm{m}^{-2} \mathrm{~h}^{-1}\right]$} & $-4.3(-27 \text { to } 14)^{\mathrm{c}}$ & $-2.1(-41 \text { to } 26)^{\mathrm{c}}$ & $0.2 \mathrm{~b}(-33 \text { to } 29)^{\mathrm{c}}$ \\
\hline Deposition velocity, mean \pm std & {$\left[\mathrm{cm} \mathrm{s}^{-1}\right]$} & $0.10 \pm 0.16$ & $0.05 \pm 0.16$ & {$[-]$} \\
\hline Number of determinations & {$[-]$} & 327 & 355 & 139 \\
\hline \multicolumn{5}{|l|}{ Atmospheric $\mathrm{CO}_{2}$} \\
\hline $\mathrm{CO}_{2}$ gradient $^{\mathrm{a}}$, day, mean & {$\left[\mathrm{ppm} \mathrm{m}{ }^{-1}\right]$} & $9.3(-1.4 \text { to } 19)^{\mathrm{c}}$ & $3.4(-7.6 \text { to } 9.6)^{\mathrm{c}}$ & $7.8(-6.1 \text { to } 18)^{\mathrm{c}}$ \\
\hline $\mathrm{CO}_{2}$ gradient $^{\mathrm{a}}$, night, mean & {$\left[\mathrm{ppm} \mathrm{m}^{-1}\right]$} & $-28(-70 \text { to } 2.0)^{\mathrm{c}}$ & $-43(-170 \text { to } 12)^{\mathrm{c}}$ & $-36(-220 \text { to } 0.1)^{\mathrm{c}}$ \\
\hline $\mathrm{CO}_{2}$ flux, $\mathrm{EC}^{\mathrm{e}}$, mean & {$\left[\mu \mathrm{mol} \mathrm{m}^{-2} \mathrm{~s}^{-1}\right]$} & $-6.4(-44 \text { to } 58)^{\mathrm{c}}$ & $3.6(-40 \text { to } 33)^{\mathrm{c}}$ & $-5.3(-23 \text { to } 18)^{\mathrm{c}}$ \\
\hline $\mathrm{CO}_{2}$ flux, aerodynamic, mean & {$\left[\mu \mathrm{mol} \mathrm{m}^{-2} \mathrm{~s}^{-1}\right]$} & $-5.4(-64 \text { to } 61)^{\mathrm{c}}$ & $17.9(-50 \text { to } 95)^{\mathrm{c}}$ & $-2.3(-27 \text { to } 45)^{\mathrm{c}}$ \\
\hline
\end{tabular}

a calculated as described in Sect. 2.5

$\mathrm{b}$ not significantly different from zero

$c$ range

d standard error

e determined by eddy covariance

${ }^{\mathrm{f}}$ minimum resolvable gradient as mean +1 std. 
therefore resorted to two more empirical methods. The first, the aerodynamic technique, is an application of Fick's law of diffusion to the turbulent atmosphere (Baldocchi, 2006). Translated to an atmospheric trace gas the general relationship for the flux is

$F_{x}=-K_{x} \frac{\partial c_{x}}{\partial z}$

where $F_{x}$ is the vertical trace gas flux, $K_{x}$ the eddy diffusivity and $\partial c_{x} / \partial z$ the concentration gradient of an arbitrary, non reactive trace gas $x$ (Dabberdt et al., 1993; Lenschow, 1995; Baldocchi, 2006). Corresponding equations have been formulated for the momentum flux $\left(Q_{M}\right)$ as well as the fluxes of sensible $\left(Q_{H}\right)$ and latent heat $\left(Q_{E}\right)$. It is assumed that the sources and sinks of these scalars are equal and thus similarity between the eddy diffusivities $\left(K_{x}=K_{H}=K_{E}\right)$ are implied.

The eddy diffusivity $K_{x}$ is expressed by the aerodynamic method as

$K_{x}=\frac{k \times u_{*} \times z}{\Phi_{h}(z / L)}$

where $k$ denotes the von Karman constant $(0.4), u_{*}$ the friction velocity, $z$ the measurement height, $\Phi_{h}(z / L)$ the universal temperature profile and $L$ the Monin-Obukhov length. Generally the eddy covariance technique is used to determine the friction velocity and $L$ is calculated from $u_{*}$, air temperature, air density and the sensible heat flux. By combination of Eq. (1) and Eq. (2) and subsequent integration we obtain

$F_{\mathrm{GEM}}=-\frac{k \times u_{*} \times\left(c_{\mathrm{GEM} z_{2}}-c_{\mathrm{GEM} z_{1}}\right)}{\log \left(z_{2} / z_{1}\right)+\psi_{z_{2}}-\psi_{z_{1}}}$

where $\psi_{z_{1}}$ and $\psi_{z_{2}}$ are the integrated similarity functions for heat at the measured heights. A more detailed description of this method is given in Edwards et al. (2005).

The second method employed is the modified Bowen ratio method, which is a slightly more direct technique to estimate the GEM flux. This method uses directly measured fluxes of a surrogate scalar (i.e. sensible heat or a second trace gas) and the vertical gradient of this scalar. In our studies we measured the fluxes of $\mathrm{CO}_{2}$ with eddy covariance and its vertical gradient concurrently with the GEM gradients. The GEM flux is then calculated as

$F_{\mathrm{GEM}}=F_{\mathrm{CO}_{2}} \times \frac{\Delta c_{\mathrm{GEM}}}{\Delta c_{\mathrm{CO}_{2}}}$

Further details and previous applications of this method are described by e.g. Meyers et al. (1996) and Lindberg and Meyers (2001).

\subsection{Instrumentation}

Air concentrations of GEM were measured in 5-min intervals with a dual cartridge mercury vapour analyser (Tekran 2536A, Tekran, Toronto, Canada). With this instrument mercury is preconcentrated by amalgamation and detected via cold vapour atomic fluorescence spectrometry; further details of its operation principals are described in e.g. Lindberg et al. (2000). The instrument was calibrated automatically every $24 \mathrm{~h}$ by means of an internal mercury permeation source. Additional, manual calibrations were performed prior to each measurement campaign by injecting mercury vapour with standard gas tight syringes from a mercury vapour generation unit (Model 2505, Tekran, Toronto, Canada).

In order to compute GEM fluxes by the MBR method $\mathrm{CO}_{2}$ concentrations were measured with a closed path infrared gas analyser (LI-6262, LI-COR Inc., Lincoln, Nebraska, USA) at a frequency of $1 \mathrm{~Hz}$. Before each campaign the gas analyser was calibrated with argon as zero gas and pressurised air with $451 \mathrm{ppm} \mathrm{CO} 2$ as span gas. The zero-offset of argon relative to a $\mathrm{N}_{2} / \mathrm{O}_{2}$ gas mixture was $0.4 \mathrm{ppm}$.

Meteorological data (air temperature, net radiation, PAR, humidity, wind speed, wind direction) were recorded by the micrometeorological instrumentation of the towers at the study sites. Carbon dioxide and water vapour fluxes were determined by eddy covariance using three-dimensional sonic anemometers and open path infrared gas analysers (Solent R2 and R3, Gill Ltd., Lymington, UK, and LI-7500, LI-COR Inc., Lincoln, Nebraska, USA).

\subsection{Measurement setup}

The measurements were performed between June and September 2006 for two weeks at each site using the same instruments. Vertical concentration gradients were determined by measuring GEM and $\mathrm{CO}_{2}$ at 5 heights above ground $(0.2$, $0.3,1.0,1.6$ and $1.7 \mathrm{~m}$ ). The same setup was installed at all three sites, although the lowest sampling heights had to be adjusted to the local height of the vegetation $(10-60 \mathrm{~cm}$ at Fruebuel and Neustift, and $10-20 \mathrm{~cm}$ at Oensingen). The sampling lines consisting of $1 / 4$ "-tubing were mounted to a mast in the vicinity of the micrometeorological towers and connected to a 5 port solenoid switching unit. Depending on space and the setup of the micrometeorological equipment at each site, the sampling lines were between $7 \mathrm{~m}$ and $15 \mathrm{~m}$ long. All lines had equal lengths and were cleaned before each measurement series. Downstream of the switch unit, the Tekran instrument and the $\mathrm{CO}_{2}$ analyser were connected in series. Filter cartridges with $0.2 \mu \mathrm{m}$ Teflon ${ }^{\circledR}$ filters were mounted to the inlets of the sampling lines to prevent contamination of the analytical system. Tubing and fittings made of Teflon ${ }^{\circledR}$ were used and cleaned with $\mathrm{HNO}_{3}$ and deionised water according to an internal standard operating procedure (adapted from Keeler and Landis, 1994). The system was checked for contamination by measuring 
mercury-free air generated by a zero air generator (Model 1100, Tekran, Toronto, Canada) before and after each measurement series. Additionally, by constricting the sampling lines temporarily it was tested if the setup had any leaks.

Air was sampled at a flow rate of $1.51 \mathrm{~min}^{-1}$ by the internal pump of the Tekran instrument. To maintain continuous flushing of all sampling tubes an auxiliary pump with a flow rate of $6.01 \mathrm{~min}^{-1}$ was connected to the four lines that were currently not sampled. The sampled air was not dried, which required correction of the calculated fluxes for density effects (see below).

Air sampling was switched from a line at a lower height to one at an upper height every $10 \mathrm{~min}$ (i.e. the sequence with the heights mentioned above was $0.2-1.6-0.3-1.7-1.0 \mathrm{~m})$. In this way a vertical concentration profile with five measurement points could be determined every $50 \mathrm{~min}$. Higher frequencies were not feasible as the low ambient GEM concentrations require pre-concentration by the gold cartridges of the Tekran intrument for accurate analysis.

\subsection{Flux calculations}

Upon completion of the measurement campaigns, GEM and $\mathrm{CO}_{2}$ fluxes were computed with a self-programmed Matlab ${ }^{\circledR}$ algorithm. Carbon dioxide fluxes were calculated to evaluate the quality of the GEM fluxes. By comparing the $\mathrm{CO}_{2}$ fluxes determined by the aerodynamic method with the $\mathrm{CO}_{2}$ fluxes obtained by eddy covariance we could assess the reliability of the aerodynamic method, i.e. matching $\mathrm{CO}_{2}$ fluxes lend credibility to the calculated GEM fluxes (assuming the $\mathrm{CO}_{2}$ fluxes determined by EC to be accurate).

After correction of the GEM and $\mathrm{CO}_{2}$ concentrations with respect to the measured standards the atmospheric concentration trend was subtracted from the data by interpolating the concentration measured at the top sampling line to the measurements of the other lines. This step was considered essential as atmospheric concentrations changed during the course of a measurement cycle of $50 \mathrm{~min}$ (i.e. $20 \mathrm{~min}$ for one height pair) and overlaid the measured gradients. Next, GEM and $\mathrm{CO}_{2}$ fluxes were calculated according to Eq. (3) and Eq. (4) for four successive height pairs per measurement cycle. The raw fluxes were then obtained by computing the median of these four values, thus reducing uncertainty substantially.

As the sampled air was not dried the raw fluxes were corrected for density effects of water vapour according to Webb et al. (1980). A correction for sensible heat was not considered necessary, because the sample air of all lines was brought to a common temperature before reaching the analysers and because the Tekran instrument monitors the GEM concentration relative to the sampled air mass with a mass flow controller. Finally, the GEM and $\mathrm{CO}_{2}$ flux data were screened for outliers and values outside the range of the mean \pm 3 standard deviations of the whole period were rejected.

\section{Results}

\subsection{Data coverage}

We performed our measurements at the three sites under fair weather conditions. However, due to power outages and showers during thunderstorms as well as instrument failures, not all variables required to calculate the GEM and $\mathrm{CO}_{2}$ fluxes could be measured continuously. As shown in Table 1 GEM fluxes could be computed for up to $85 \%$ of the measurement periods. In Neustift and Oensingen the data coverage of the GEM fluxes calculated by the MBR method was considerably reduced due to failure of the eddy covariance systems.

As the resolution of gradient measurements is limited we determined the minimum resolvable gradient (MRG) in a similar way as described by Edwards et al. (2005). This was done once at Fruebuel by mounting all five sampling lines at $1 \mathrm{~m}$ above ground, measuring the GEM and $\mathrm{CO}_{2}$ concentrations for three days and computing the concentration differences between the line pairs used for the flux calculations. By defining the MRG as the mean of the concentration differences plus one standard deviation we obtained MRG's of $0.02 \mathrm{ng} \mathrm{m}^{-3}$ for GEM and $2.5 \mathrm{ppm}$ for $\mathrm{CO}_{2}$. This translates to minimum GEM fluxes determinable with the aerodynamic method of -2.8 to $-4.6 \mathrm{ng} \mathrm{m}^{-2} \mathrm{~h}^{-1}$ for typical daytime and -0.5 to $-1.9 \mathrm{ng} \mathrm{m}^{-2} \mathrm{~h}^{-1}$ for typical night-time turbulence regimes (for daytime $u_{*}=0.17$ to $0.27 \mathrm{~m} \mathrm{~s}^{-1}$ and $z / L=-0.49$ to -0.16 ; for night-time $u_{*}=0.032$ to $0.11 \mathrm{~m} \mathrm{~s}^{-1}$ and $z / L=2.2$ to 0.15 , data from the Fruebuel site). As the MRG is system-specific, the values gained at Fruebuel were also applied to the measurements at Neustift and Oensingen. Excluding outliers and flux values with gradients below the MRG, the overall data coverage for the GEM fluxes at the three sites was between 27 and 58\% (see Table 1 for details). However, exchange rates calculated with smaller gradients than the MRG were included in the results reported below, as average fluxes would otherwise be overestimated.

\subsection{Meteorological conditions}

Meteorological conditions at the three sites were mainly sunny and stationary most of the time (see Fig. 1 to 3 and Table 1). The measurement campaign in Oensingen was scheduled for September 2006 when air temperature and irradiation were somewhat lower than at the other sites. However, conditions in Oensingen were unstable and very humid with evening and night-time thunderstorms. Friction velocity at Fruebuel and Neustift was very similar with average values of $0.17 \mathrm{~m} \mathrm{~s}^{-1}$. The value for Oensingen was lower with $0.12 \mathrm{~m} \mathrm{~s}^{-1}$. At the national air monitoring stations nearest to Fruebuel and Oensingen average $\mathrm{O}_{3}$ concentrations of 123 and $25 \mu \mathrm{g} \mathrm{m}^{-3}$, respectively, were measured during the study periods. 

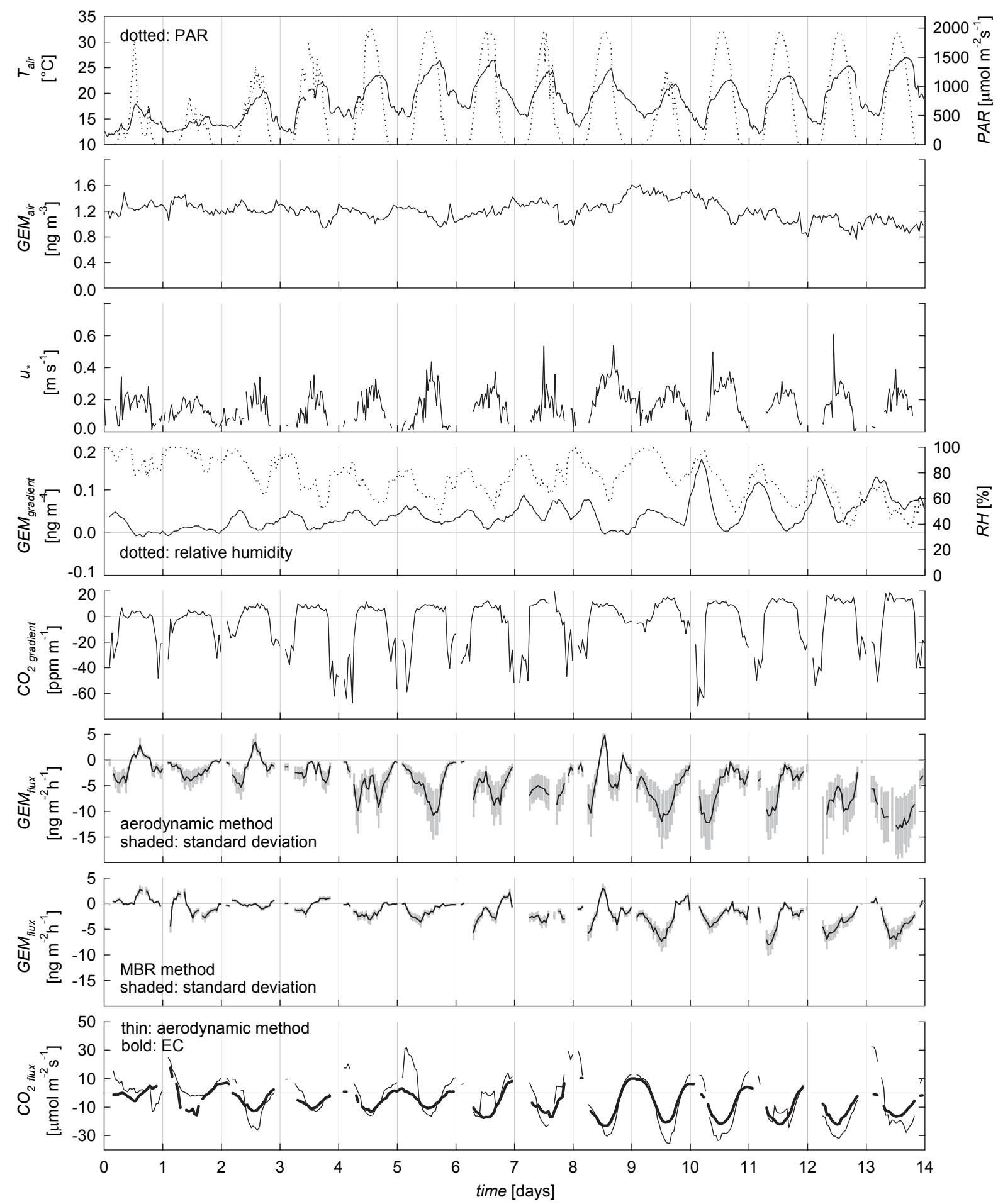

Fig. 1. Time series of measurements at Fruebuel. From top to bottom: air temperature $\left(T_{\text {air }}\right)$, photosynthetically active radiation (PAR), atmospheric GEM concentration at $1.7 \mathrm{~m}$ above ground $\left(\mathrm{GEM}_{\text {air }}\right)$, friction velocity $\left(u_{*}\right)$, GEM gradients and relative humidity, $\mathrm{CO}_{2}$ gradients, turbulent fluxes of GEM (determined by the aerodynamic and $\mathrm{MBR}$ methods) and $\mathrm{CO}_{2}$ (determined by the aerodynamic method and the eddy covariance technique). Flux data and GEM gradients were filtered by a 7-point moving average. Positive fluxes indicate emission, negative deposition. 

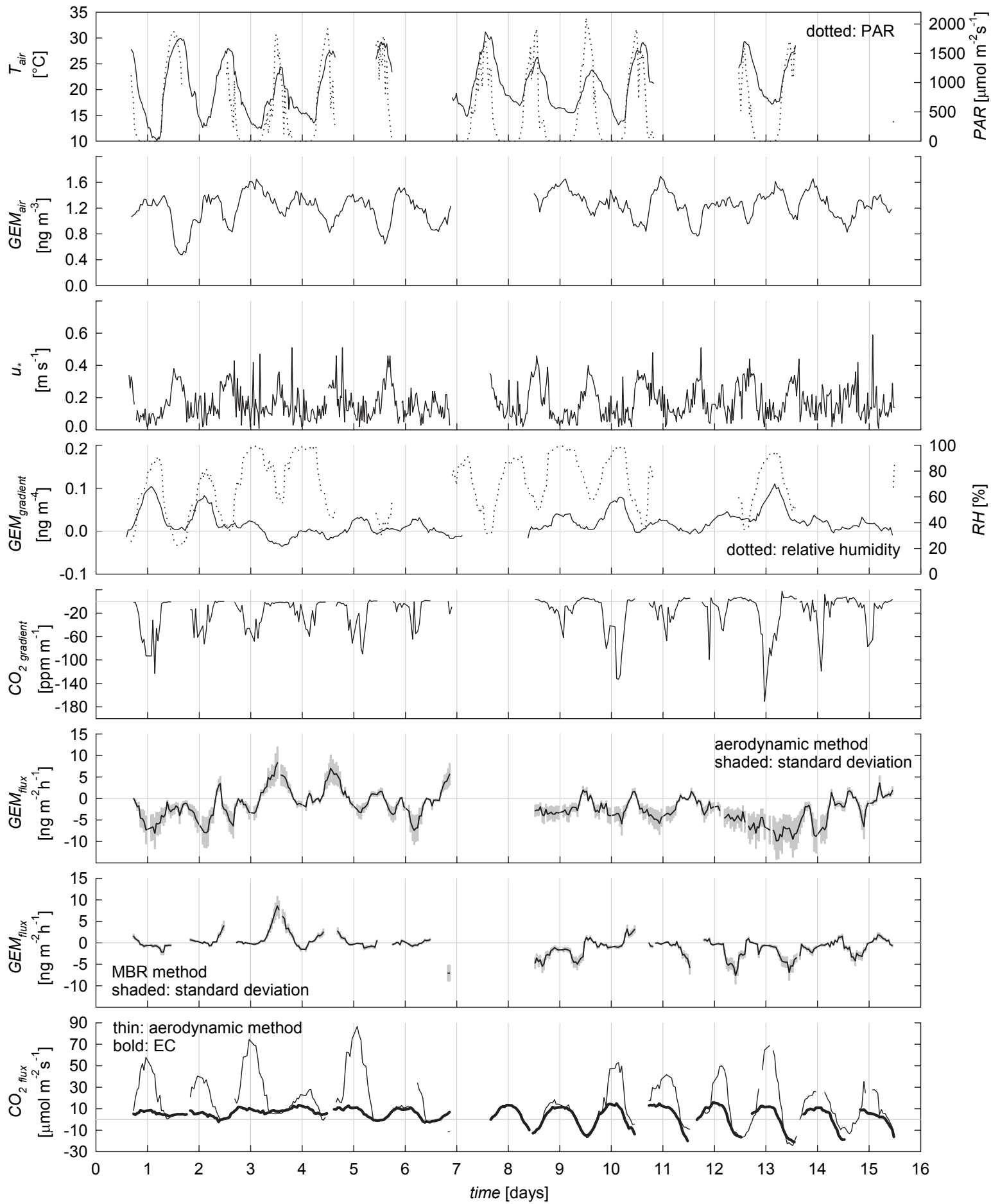

Fig. 2. Same as Fig. 1, but for study site Neustift. 

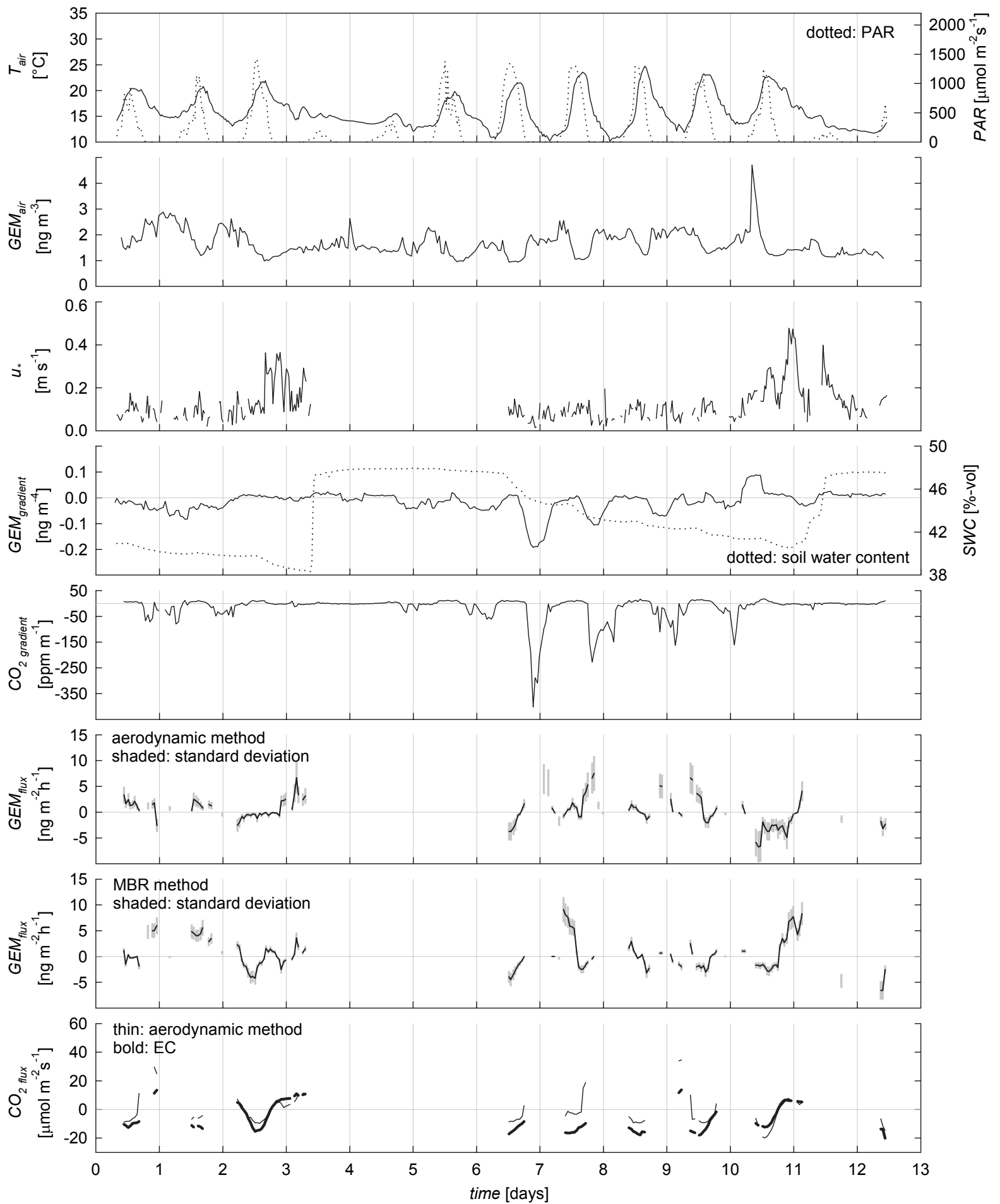

Fig. 3. Same as Fig. 1, but study site Oensingen. Soil water content is shown instead of relative humidity in panel four. 
Table 2. Correlation of GEM concentration with meteorological variables.

\begin{tabular}{|c|c|c|c|c|c|c|}
\hline \multirow[t]{2}{*}{ Variable } & \multicolumn{2}{|c|}{ Fruebuel $^{\mathrm{b}}$} & \multicolumn{2}{|c|}{ Neustift $^{\mathrm{c}}$} & \multicolumn{2}{|c|}{ Oensingen $^{d}$} \\
\hline & $\mathrm{r}$ & $\mathrm{p}$ & $\mathrm{r}$ & $\mathrm{p}$ & $\mathrm{r}$ & $\mathrm{p}$ \\
\hline Air temperature & -0.39 & $<0.05$ & -0.77 & $<0.05$ & -0.30 & $<0.05$ \\
\hline Soil temperature & -0.28 & $<0.05$ & -0.64 & $<0.05$ & -0.26 & $<0.05$ \\
\hline PAR & -0.17 & $<0.05$ & -0.56 & $<0.05$ & -0.27 & $<0.05$ \\
\hline Soil water content & 0.44 & $<0.05$ & 0.31 & $<0.05$ & -0.30 & $<0.05$ \\
\hline Absolute humidity & 0.44 & $<0.05$ & 0.65 & $<0.05$ & -0.08 & 0.14 \\
\hline Relative humidity & 0.66 & $<0.05$ & 0.82 & $<0.05$ & 0.47 & $<0.05$ \\
\hline $\mathrm{CO}_{2}$ concentration (LI 6262) & 0.11 & $<0.05$ & 0.31 & $<0.05$ & 0.66 & $<0.05$ \\
\hline $\mathrm{CO}_{2}$ flux (eddy covariance) & 0.21 & $<0.05$ & 0.09 & 0.15 & -0.03 & 0.81 \\
\hline $\mathrm{H}_{2} \mathrm{O}$ flux (eddy covariance) & -0.16 & $<0.05$ & -0.61 & $<0.05$ & -0.52 & $<0.05$ \\
\hline $\mathrm{O}_{3}$ concentration $^{\mathrm{a}}$ & -0.43 & $<0.05$ & {$[-]$} & {$[-]$} & -0.54 & $<0.05$ \\
\hline Wind speed & 0.05 & 0.35 & -0.52 & $<0.05$ & -0.33 & $<0.05$ \\
\hline
\end{tabular}

a data from nearest national monitoring station; ${ }^{\mathrm{b}} \mathrm{N}=255-390 ;{ }^{\mathrm{c}} \mathrm{N}=194-375 ;{ }^{\mathrm{d}} \mathrm{N}=31-337$

\subsection{Atmospheric GEM concentrations}

Average atmospheric GEM concentrations measured $1.7 \mathrm{~m}$ above ground were $1.2 \pm 0.2 \mathrm{ng} \mathrm{m}^{-3}$ at both, the Fruebuel and Neustift sites, and $1.7 \pm 0.5 \mathrm{ng} \mathrm{m}^{-3}$ at the site in Oensingen (see Table 1). The highest concentration was measured in Oensingen during daytime with $4.7 \mathrm{ng} \mathrm{m}^{-3}$, the lowest in Neustift with $0.5 \mathrm{ng} \mathrm{m}^{-3}$ during the night (see Fig. 1 to 3 ). As can be seen in Fig. 4 the concentrations in Neustift and Oensingen followed a distinct diurnal pattern with lowest GEM concentrations in the afternoon between 14 and $15 \mathrm{~h}$. This pattern was particularly pronounced in Neustift with an average diurnal amplitude of $0.32 \mathrm{ng} \mathrm{m}^{-3}$. In contrast, a diurnal signal at Fruebuel was absent and concentrations nearly constant.

Calculation of the correlation coefficients between ambient GEM concentration and meteorological variables revealed moderate linear relationships with relative humidity and atmospheric $\mathrm{O}_{3}$ at Fruebuel and Oensingen (see Table 2). More pronounced correlations of GEM concentration were detected in Neusitft for most variables, notably air temperature and PAR, but no $\mathrm{O}_{3}$ record was available for this site.

\section{4 $\mathrm{CO}_{2}$ and GEM fluxes}

In Table 1 a summary of the average GEM and $\mathrm{CO}_{2}$ gradients and fluxes is given for the investigated sites; the corresponding time series are shown in Fig. 1 to 3. Due to large spread, fluxes and GEM gradients were smoothed with a 7point moving average (which corresponds to an interval of $\sim 8 \mathrm{~h}$ ). As expected, the vertical concentration gradients and fluxes of $\mathrm{CO}_{2}$ varied substantially between day and night. While the highest average day-time gradient $(9-15 \mathrm{~h})$ was recorded at Fruebuel with $9.3 \mathrm{ppm} \mathrm{m}^{-1}$, the highest average night-time gradient $(23-5 \mathrm{~h})$ was measured in Neustift with

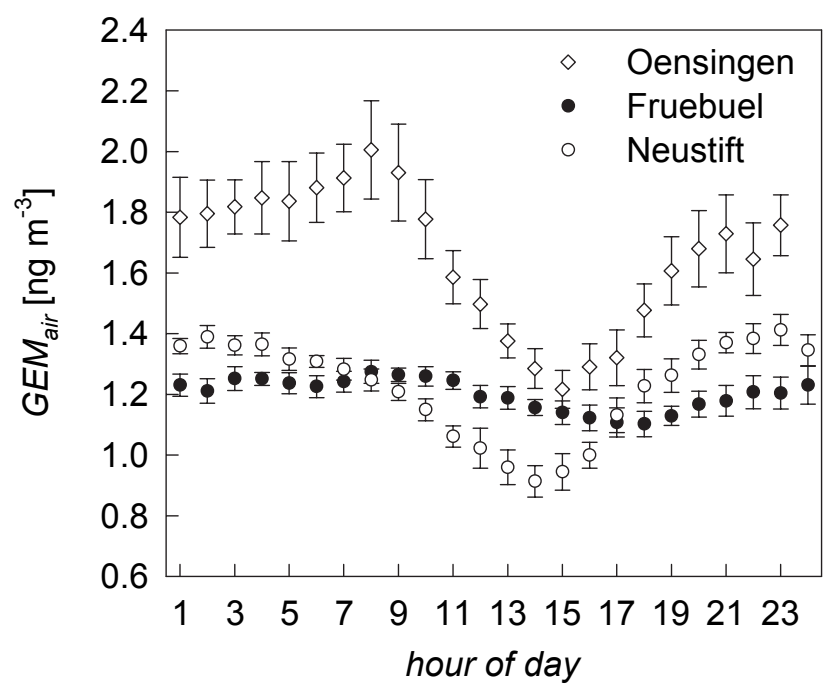

Fig. 4. Diurnal trend of atmospheric GEM concentrations at the three study sites. Shown are hourly mean and standard errors of all measurement days (Fruebuel 14 days, Neustift 16 days, Oensingen 11 days).

$-43 \mathrm{ppm} \mathrm{m}^{-1}$. The largest gradient of $-220 \mathrm{ppm} \mathrm{m}^{-1}$ was measured at Oensingen during one night.

As mentioned in the experimental section $\mathrm{CO}_{2}$ fluxes were determined two-fold, with eddy covariance and the aerodynamic method. The former yielded on average a net uptake or deposition of $6.4 \mu \mathrm{mol} \mathrm{m}{ }^{-2} \mathrm{~s}^{-1}$ and $5.3 \mu \mathrm{mol} \mathrm{m}^{-2} \mathrm{~s}^{-1}$ at Fruebuel and Oensingen, respectively, and a mean net $\mathrm{CO}_{2}$ emission of $3.6 \mu \mathrm{mol} \mathrm{m}^{-2} \mathrm{~s}^{-1}$ in Neustift. With the aerodynamic method average deposition of $5.4 \mu \mathrm{mol} \mathrm{m}^{-2} \mathrm{~s}^{-1}$ and $2.3 \mu \mathrm{mol} \mathrm{m}^{-2} \mathrm{~s}^{-1}$ were estimated for Fruebuel and Oensingen, and mean emissions of $17.9 \mu \mathrm{mol} \mathrm{m}^{-2} \mathrm{~s}^{-1}$ for Neustift (only data overlapping with the EC data were considered). 
Over the two-week period at Fruebuel $\mathrm{CO}_{2}$ fluxes showed a linear trend towards higher deposition rates.

At all three sites GEM gradients showed a diurnal pattern, which was more pronounced at Fruebuel than at Neustift and Oensingen. Gradients were extremely small with a maximum value of $0.40 \mathrm{ng} \mathrm{m}^{-3} \mathrm{~m}^{-1}$ at Oensingen. Average day-time gradients reached $0.02 \mathrm{ng} \mathrm{m}^{-3} \mathrm{~m}^{-1}$ at Fruebuel and were below the minimum resolvable gradient at Neustift and Oensingen. With $0.06 \mathrm{ng} \mathrm{m}^{-3} \mathrm{~m}^{-1}$ the mean night-time gradient was highest at Fruebuel; for Neustift and Oensingen mean values of 0.02 and $-0.04 \mathrm{ng} \mathrm{m}^{-3} \mathrm{~m}^{-1}$ were calculated. At Neustift and Fruebuel night-time gradients were highest in the early morning around 05:00 a.m. In contrast, night-time gradients at Oensingen were negative between measurement days 6 and 10, and peaked before midnight. Figure 1 also shows, that the amplitude of the GEM gradient at Fruebuel increased over time.

Computation of the fluxes yielded on average a small deposition of GEM at Fruebuel and Neustift and slight emission in Oensingen. At Fruebuel, the average GEM fluxes determined by the MBR method and the aerodynamic method were -1.6 and $-4.3 \mathrm{ng} \mathrm{m}^{-2} \mathrm{~h}^{-1}$, respectively. The corresponding exchange rates in Neustift were -0.5 and $-2.1 \mathrm{ng} \mathrm{m}^{-2} \mathrm{~h}^{-1}$ and in Oensingen 0.3 and $0.2 \mathrm{ng} \mathrm{m}^{-2} \mathrm{~h}^{-1}$. The latter two values as well as the exchange rate determined by MBR at Neustift were not significantly different from zero. The highest variability of the fluxes was recorded for Neustift with a range of -76 to $37 \mathrm{ng} \mathrm{m}^{-2} \mathrm{~h}^{-1}$, determined with the aerodynamic method. At Fruebuel fluctuations were smallest with a range of -14 to $14 \mathrm{ng} \mathrm{m}^{-2} \mathrm{~h}^{-1}$, again determined with the aerodynamic method. Average deposition velocities $\left(v_{d}=-F_{\mathrm{GEM}} / c_{\mathrm{GEM}}\right)$ for Fruebuel and Neustift were calculated to be 0.04 and $0.01 \mathrm{~cm} \mathrm{~s}^{-1}$ for the MBR method as well as 0.10 and $0.05 \mathrm{~cm} \mathrm{~s}^{-1}$ for the aerodynamic method. A linear trend of the GEM flux overlaid by a diurnal pattern with increasing amplitude was observed at Fruebuel. No such trend existed at Neustift and Oensingen and diurnal fluctuations were only visible during some periods and were more pronounced by the aerodynamic method.

\section{Discussion}

\subsection{Evaluation of micrometeorological methods}

As every micrometeorological method, flux-gradient techniques have certain limitations. One constraint is the footprint that depends on the prevailing atmospheric conditions, site heterogeneity and measurement height. When measuring gradients, the fetch of an upper sampling height is greater than the one at a lower sampling height and therefore generates some uncertainty. A further error is introduced by measuring in the so-called roughness sublayer, the region adjacent to the vegetation, that is directly affected by the growing plants. In this zone common flux-gradient relationships become progressively less reliable as the gradient measurements approach the vegetated surface (Raupach and Legg, 1984; Baldocchi, 2006). For some periods this uncertainty had to be accepted in our study, as the measurements ran autonomously and the sampling lines could not be adjusted to the growing vegetation. Overall, errors associated with the aerodynamic method range between 10 and $30 \%$ and are greatest during periods with little turbulence (Baldocchi et al., 1988). Additionally, the MBR method assumes that the transport processes are identical for both species, i.e. GEM and $\mathrm{CO}_{2}$ (Lenschow, 1995). In the roughness sublayer this assumption is not guaranteed and might be another source of uncertainty.

In general, the MBR method yielded smaller average fluxes than the aerodynamic technique and on shorter time scales fluxes often differed considerably. The discrepancies of the averaged fluxes are likely to be of methodological nature as the methods differ in the way how they use the gradients to obtain the fluxes. While the aerodynamic method uses universal, empirical relationships to correct for atmospheric stability, the MBR approach relies on the accurate flux determination of the surrogate scalar by an independent method. The short-term fluctuations on the other hand are primarily the result of non-synchronous concentration measurements at the various heights as well as the rather low instrumental resolution of one flux value per $50 \mathrm{~min}$ and the small GEM gradients, which were around the minimum resolvable gradient of $0.02 \mathrm{ng} \mathrm{m}^{-3}$.

To evaluate the quality of the GEM fluxes, $\mathrm{CO}_{2}$ exchange rates were also estimated with the aerodynamic method and compared to the EC $\mathrm{CO}_{2}$ fluxes. Figures 1 and 2 illustrate that during some periods the aerodynamic technique strongly overestimated night-time fluxes relative to the EC method. In the stable nocturnal boundary layer, when $u_{*}$ is small $\left(<0.1 \mathrm{~m} \mathrm{~s}^{-1}\right)$, turbulent exchange is inhibited and vertical concentration gradients increase. Moreover, the aerodynamic method is based on the momentum flux equation as well as the wind speed/gradient relationship and requires some empirical formulae to describe atmospheric stability (Baldocchi et al., 1988). Uncertainties in these stability functions result in erroneous flux estimates for conditions of low turbulence (this limitation also applies to the GEM fluxes).

At Fruebuel we also obtained enhanced $\mathrm{CO}_{2}$ fluxes by the aerodynamic gradient method during the day. This overestimation relative to the EC method might indicate that the gradient was measured too close to the vegetation cover when the grass grew closer to the lower sampling lines. Within and adjacent to the plant cover the universal flux-gradient relationships are no longer valid. Two additional problems may contribute to the observed discrepancy of the measured fluxes: I) When measuring gradients too close to the canopy, sources and sinks of $\mathrm{CO}_{2}$ may not be equal any more and II), the footprints that are covered by the sampling lines at different heights are not identical. These considerations would lend more credibility to the GEM fluxes determined 


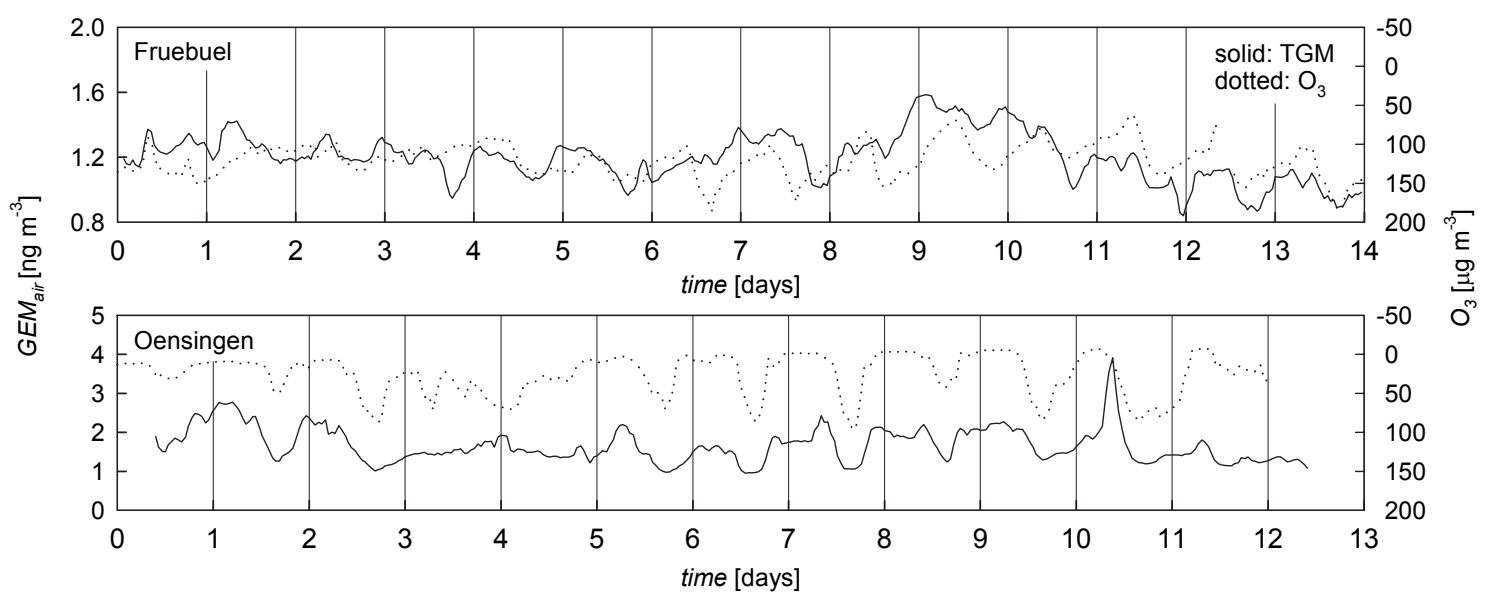

Fig. 5. Time series of atmospheric GEM and ozone concentrations $\left(\mathrm{O}_{3}\right)$ at Fruebuel and Oensingen. GEM concentrations were filtered by a 3-point moving average. One $\mu \mathrm{g} \mathrm{m}^{-3}$ of $\mathrm{O}_{3}$ corresponds to $0.5 \mathrm{ppb}$.

by MBR, as this method uses the ratio of the GEM and $\mathrm{CO}_{2}$ gradients and appears thus more robust. However, due to complex vertical distributions of sources and sinks of trace gases within terrestrial ecosystems, the theoretical basis for the MBR method may be generally questioned. Yet, there are several examples in the literature (e.g. Doskey et al., 2004; Muller et al., 1993; Walker et al., 2006) which have shown that despite this shortcoming, the MBR yields sensible, unbiased flux estimates.

The comparison presented in our manuscript suggests that the aerodynamic method yields more reliable GEM fluxes than the MBR method. This may actually be due to the fact that during daytime conditions the net flux of $\mathrm{CO}_{2}$ - the surrogate scalar of the MBR method - is dominated by plant photosynthesis (uptake of $\mathrm{CO}_{2}$ from the atmosphere), obscuring the release of $\mathrm{CO}_{2}$ from the soil surface. As the soil is thought to represent the major source of GEM this would clearly invalidate the theoretical basis of the MBR method.

\subsection{Atmospheric GEM concentrations}

The mean global GEM concentration is reported to be around $1.7 \mathrm{ng} \mathrm{m}^{-3}$ (Valente et al., 2007). In Europe Munthe and Wängberg (2001) measured concentrations of $1.34 \mathrm{ng} \mathrm{m}^{-3}$ at Pallas in Finnland and Kim et al. (2005) $1.55 \mathrm{ng} \mathrm{m}^{-3}$ at Mace Head in Ireland. The average concentrations of 1.20 to $1.66 \mathrm{ng} \mathrm{m}^{-3}$ that we measured at our sites are consistent with these observations.

Moderate correlations of GEM concentration with atmospheric $\mathrm{O}_{3}$ and relative humidity were detected at Fruebuel and Oensingen (see Table 1 and Fig. 5). These correlations and the diurnal patterns of GEM and $\mathrm{O}_{3}$ support the notion that $\mathrm{O}_{3}$ is an effective reactant to remove $\mathrm{Hg}^{0}$ from the atmosphere (Hall, 1995). Additionally, hydroxyl radicals, which have the power to oxidise $\mathrm{Hg}^{0}$ (Lin and Pehkonen, 1999) and which are formed by the reaction of water vapour with photolysed ozone, may explain our observed correlation with relative humidity. However, our results do not provide clear evidence that oxidation by $\mathrm{O}_{3}$ or hydroxyl radicals is responsible for the observed GEM depletion.

\subsection{GEM exchange between atmosphere and grassland}

With average GEM gradients between 0.02 and $0.06 \mathrm{ng} \mathrm{m}^{-3} \mathrm{~m}^{-1}$, ranging from -0.40 to $0.27 \mathrm{ng} \mathrm{m}^{-3} \mathrm{~m}^{-1}$ our results are comparable to gradients measured in other ecosystems. For example, Lindberg and Meyers (2001) measured GEM gradients of $0.03 \pm 0.03 \mathrm{ng} \mathrm{m}^{-3} \mathrm{~m}^{-1}$ over wetland vegetation, Kim et al. (1995) determined values of -0.16 to $0.32 \mathrm{ng} \mathrm{m}^{-3}$ (over $1.4 \mathrm{~m}$ ) above forest soils in eastern Tennessee and Lindberg et al. (1998) measured gradients of -0.091 to $0.064 \mathrm{ng} \mathrm{m}^{-3} \mathrm{~m}^{-1}$ over forest soils in Sweden.

Although the GEM fluxes varied rather strongly, small but statistically significant net deposition rates could be observed at Fruebuel and Neustift. Similar exchange rates - but with inconsistent flux directions - have been estimated for various ecosystems. For example, Obrist et al. (2006) measured a mean deposition rate of $0.2 \mathrm{ng} \mathrm{m}^{-2} \mathrm{~h}^{-1}$ at another montane grassland site in Switzerland. In Canada Schroeder et al. (2005) observed fluxes between -0.4 to $2.2 \mathrm{ng} \mathrm{m}^{-2} \mathrm{~h}^{-1}$ over forest soils and 1.1 to $2.9 \mathrm{ng} \mathrm{m}^{-2} \mathrm{~h}^{-1}$ over agricultural fields. Values between $-2.2 \mathrm{ng} \mathrm{m}^{-2} \mathrm{~h}^{-1}$ and $7.5 \mathrm{ng} \mathrm{m}^{-2} \mathrm{~h}^{-1}$ were also measured for forest soils by Kim et al. (1995), and Ericksen et al. (2006) determined a mean emission of $0.9 \pm 0.2 \mathrm{ng} \mathrm{m}^{-2} \mathrm{~h}^{-1}$ from different background soils across the USA. Emissions of $8.3 \mathrm{ng} \mathrm{m}^{-2} \mathrm{~h}^{-1}$ from a grassy site were measured by Poissant and Casimir (1998). In contrast, relatively high exchange rates in remote ecosystems are reported by Lindberg et al. (1992) who determined GEM 
emissions of $50 \mathrm{ng} \mathrm{m}^{-2} \mathrm{~h}^{-1}$ from contaminated forest soils and Cobos et al. (2002) who measured fluxes of -91.7 to $9.67 \mathrm{ng} \mathrm{m}^{-2} \mathrm{~h}^{-1}$ over an agricultural soil. Different methods were used in these studies and might explain some of the divergence between the findings. However, fluxes measured by our group at four different sites (Obrist et al., 2006, this study) indicate net deposition of GEM and imply that grasslands of the temperate montane climate belt are small net sinks for atmospheric mercury.

Other than at Fruebuel and Neustift our methods yielded no net flux in Oensingen. This discrepancy might be attributed to natural variability, as the observed background fluxes are already extremely low. However, during a period of three days, negative night-time GEM gradients were observed, indicating emission of mercury (due to low wind speeds no GEM fluxes could be determined; see Fig. 3). Heavy showers during thunderstorms between days 4 and 6 increased the soil water content by approx. $25 \%$, which started to drop again during day six. It appears that the observed GEM gradients during this period are linked to the shift in soil moisture. On the other hand, it is also plausible that this pattern resulted from advection of low GEMcontaining air that may be associated with the insufficient fetch of this site during night-times.

At Fruebuel and Neustift night-time GEM gradients followed the pattern of relative humidity. Therefore, we suggest that during the night GEM was co-deposited with water condensing on the vegetation surfaces. Although incorporation of mercury into the plant material is conceivable, GEM was eventually re-emitted from the plant surface in the morning when temperature increased and water evaporated again. This re-emission might take place at a fast rate during a short interval that is not resolvable with our measurement technique.

A linear trend of the GEM flux could be observed at Fruebuel, resulting from the growing vegetation after a grass cut at the beginning of the campaign. In part this trend is artificial as the growing grass increases the atmospheric roughness sublayer, thereby reducing turbulence and enhancing the GEM gradients. However, with increasing plant surface area more GEM may be adsorbed by vegetation and adds to the positive gradients. The unbiased part of the trend is reflected in the $\mathrm{CO}_{2}$ flux estimated by EC, the method that is independent of gradients measurements. In Neustift, where the grass was also cut at the start of the measurement campaign, no such trend was visible. The flux signal rather seems to have a component with a periodicity of 4 to 5 days that conceals any long-term trend. Further investigations would be required at this site to ascertain the processes resulting in this signal.

\section{Conclusions}

In order to estimate air-surface GEM fluxes of uncontaminated grasslands along the Swiss and Austrian Alps we applied two micrometeorological methods. Both, the aerodynamic and the MBR methods proved suitable to estimate net exchange rates on time scales of a few hours and longer. Due to the required pre-concentration technique for the detection of GEM, fluxes could not be resolved sufficiently on shorter time scales.

With respect to gaseous exchange our results suggest that grasslands of the temperate montane climate are a net sink for atmospheric mercury. This sink is very small compared to emissions of contaminated and naturally enriched areas (these are in the order of 100 to $>1000 \mathrm{ng} \mathrm{m}^{-2} \mathrm{~h}^{-1}$ ). Nonetheless, deposition could add significant quantities of mercury to remote terrestrial ecosystems if these fluxes are confirmed in other locations. On the condition that deposited mercury is stably bound in the pedosphere, this would also entail a long-term reduction in atmospheric mercury.

At two of our sites we observed day-time depletion of GEM, which may be attributed to the oxidation of GEM by $\mathrm{O}_{3}$ and other reactive trace gases. However, no clear cause and effect relationship could be determined. On the other hand, night-time deposition of GEM was measured frequently and seems to be the result of co-precipitation with condensing water.

Acknowledgements. We thank the Swiss National Science Foundation (project numbers: 200020-113327/1 to D. Obrist and C. Alewell; 200021-105949 to W. Eugster and R. A. Werner) and the Austrian National Science Foundation (project number: P17560-B03 to Georg Wohlfahrt) for financing this project and would like to express our appreciation to F. Conen, W. Eugster and R. Vogt for their valuable help in experimental and micrometeorological issues.

Edited by: A. Hofzumahaus

\section{References}

Baldocchi, D.: Advanced topics in biometeorology and micrometeorology: Lecture on micrometeorological flux measurement methods, http://nature.berkeley.edu/biometlab/espm228/, 2006.

Baldocchi, D., Hicks, B. B., and Meyers, T. P.: Measuring biosphere-atmosphere exchanges of biologically related gases with micrometeorological methods, Ecology, 69, 1331-1340, 1988.

Cobos, D. R., Baker, J. M., and Nater, E. A.: Conditional sampling for measuring mercury vapor fluxes, Atmos. Environ., 36, 43094321, 2002.

Dabberdt, W. F., Lenschow, D. H., Horst, T. W., Zimmerman, P. R., Oncley, S. P., and Delany, A. C.: Atmosphere-Surface Exchange Measurements, Science, 260, 1472-1481, 1993.

De Temmerman, L., Claeys, N., Roekens, E., and Guns, M.: Biomonitoring of airborne mercury with perennial ryegrass cultures, Environ. Pollut., 146, 458-462, 2007. 
Doskey, P. V., Kotamarthi, V. R., Fukui, Y., Cook, D. R., Breitbeil, F. W., and Wesely, M. L.: Air-surface exchange of peroxyacetyl nitrate at a grassland site, J. Geophys. Res.-Atmos., 109, 2004.

Du, S. H. and Fang, S. C.: Uptake of Elemental Mercury-Vapor by C3-Species and C4-Species, Environ. Exp. Bot., 22, 437-443, 1982.

Edwards, G. C., Rasmussen, P. E., Schroeder, W. H., Wallace, D. M., Halfpenny-Mitchell, L., Dias, G. M., Kemp, R. J., and Ausma, S.: Development and evaluation of a sampling system to determine gaseous Mercury fluxes using an aerodynamic micrometeorological gradient method, J. Geophys. Res.-Atmos., 110, D10306, doi:10.1029/2004JD005187, 2005.

Ericksen, J. A., Gustin, M. S., Xin, M., Weisberg, P. J., and Fernandez, G. C. J.: Air-soil exchange of mercury from background soils in the United States, Sci. Total Environ., 366, 851-863, 2006.

Fay, L. and Gustin, M.: Assessing the influence of different atmospheric and soil mercury concentrations on foliar mercury concentrations in a controlled environment, Water Air Soil Poll., 181, 373-384, 2007

Foken, T.: Angewandte Meteorologie: mikrometeorologische Methoden, Springer, Berlin, 2006.

Fritsche, J., Obrist, D., Zeeman, M., Conen, F., Eugster, W., and Alewell, C.: Elemental mercury fluxes over a sub-alpine grassland determined with two micrometeorological methods, Atmos. Environ., 42, 2922-2933, 2008.

Gustin, M. S. and Lindberg, S. E.: Terrestrial mercury fluxes: is the net exchange up, down, or neither?, in: Dynamics of mercury pollution on regional and global scales, edited by: Pirrone, N. and Mahaffey, K. R., Springer, New York, 241-259, 2005.

Hall, B.: The Gas-Phase Oxidation of Elemental Mercury by Ozone, Water Air Soil Poll., 80, 301-315, 1995.

IOMC: Global Mercury Assessment, Tech. rep., UNEP Chemicals, Geneva, 2002.

Keeler, G. J. and Landis, M. S.: Standard operating procedure for sampling vapor phase mercury, http://www.epa.gov/grtlakes/ lmmb/methods/, 1994.

Kim, K. H., Lindberg, S. E., and Meyers, T. P.: Micrometeorological Measurements of Mercury-Vapor Fluxes over Background Forest Soils in Eastern Tennessee, Atmos. Environ., 29, 267282, 1995

Kim, K.-H., Ebinghaus, R., Schroeder, W. H., Blanchard, P., Kock, H. H., Steffen, A., Froude, F. A., Kim, M.-Y., Hong, S., and Kim, J.-H.: Atmospheric Mercury Concentrations from Several Observatory Sites in the Northern Hemisphere, J. Atmos. Chem., 50, 1-24, 2005.

Kljun, N., Kastner-Klein, P., Fedorovich, E., and Rotach, M. W.: Evaluation of Lagrangian Footprint Model Using Data from Wind Tunnel Convective Boundary Layer, Agric. For. Meteorol., 127, 189-201, 2004.

Kormann, R. and Meixner, F. X.: An Analytical Footprint Model for Non-Neutral Stratification, Boundary-Layer Meteorol., 99, 207224, 2001

Lenschow, D.: Micrometeorological techniques for measuring biosphere-atmosphere trace gas exchange, in: Biogenic trace gases: measuring emissions from soil and water, edited by: Matson, P. and Harriss, R., Blackwell Science Ltd, Cambridge, 126163,1995
Lin, C. J. and Pehkonen, S. O.: The chemistry of atmospheric mercury: a review, Atmos. Environ., 33, 2067-2079, 1999.

Lindberg, S. and Meyers, T.: Development of an automated micrometeorological method for measuring the emission of mercury vapor from wetland vegetation, Wetl. Ecol. Manag., 9, 333347, 2001.

Lindberg, S., Vette, A., Miles, C., and Schaedlich, F.: Mercury speciation in natural waters: Measurement of dissolved gaseous mercury with a field analyzer, Biogeochemistry, 48, 237-259, 2000.

Lindberg, S. E., Meyers, T. P., Taylor, G. E., Turner, R., and Schroeder, W.: Atmoshere-surface exchange of mercury in a forest: Results of modeling and gradient approaches, J. Geophys. Res.-Atmos., 97, 2519-2528, 1992.

Lindberg, S. E., Kim, K. H., Meyers, T. P., and Owens, J. G.: Micrometeorological Gradient Approach for Quantifying AirSurface Exchange of Mercury-Vapor - Tests over Contaminated Soils, Environ. Sci. Technol., 29, 126-135, 1995.

Lindberg, S. E., Hanson, P. J., Meyers, T. P., and Kim, K. H.: Air/surface exchange of mercury vapor over forests - The need for a reassessment of continental biogenic emissions, Atmos. Environ., 32, 895-908, 1998.

Lindberg, S. E., Ebinghaus, R., Engstrom, D., Feng, X., Fitzgerald, W. F., Pirrone, N., Prestbo, E., and Seigneur, C.: A Synthesis of Progress and Uncertainties in Attributing the Sources of Mercury in Deposition, Ambio, 36, 19-33, 2007.

Meyers, T. P., Hall, M. E., Lindberg, S. E., and Kim, K.: Use of the modified Bowen-ratio technique to measure fluxes of trace gases, Atmos. Environ., 30, 3321-3329, 1996.

Millhollen, A., Obrist, D., and Gustin, M.: Mercury accumulation in grass and forb species as a function of atmospheric carbon dioxide concentrations and mercury exposures in air and soil, Chemosphere, 65, 889-897, 2006.

Muller, H., Kramm, G., Meixner, F., Dollard, G. J., Fowler, D., Possanzini, M.: Determination of $\mathrm{HNO}_{3}$ Dry Deposition by Modified Bowen-Ratio and Aerodynamic Profile Techniques, Tellus B, 45, 346-367, 1993.

Munthe, J. and Wängberg, I.: Atmospheric Mercury in Sweden, Northern Finland and Northern Europe, Tech. rep., IVL Swedish Environmental Research Institute, Gothenburg, 2001.

Obrist, D.: Atmospheric mercury pollution due to losses of terrestrial carbon pools?, Biogeochemistry, 85, 119-123, 2007.

Obrist, D., Conen, F., Vogt, R., Siegwolf, R., and Alewell, C.: Estimation of $\mathrm{Hg}^{0}$ exchange between ecosystems and the atmosphere using ${ }^{222} \mathrm{Rn}$ and $\mathrm{Hg}^{0}$ concentration changes in the stable nocturnal boundary layer, Atmos. Environ., 40, 856-866, 2006.

Pirrone, N. and Mahaffey, K. R.: Where we stand on mercury pollution and its health effects on regional and global scales, in: Dynamics of mercury pollution on regional and global scales, edited by: Pirrone, N. and Mahaffey, K. R., 1-21, Springer, New York, 2005.

Poissant, L. and Casimir, A.: Water-air and soil-air exchange rate of total gaseous mercury measured at background sites, Atmos. Environ., 32, 883-893, 1998.

Raupach, M. R. and Legg, B. J.: The uses and limitations of fluxgradient relationships in micrometeorology, Agr. Water Manage., 8, 119-131, 1984

Schroeder, W. H., Beauchamp, S., Edwards, G., Poissant, L., Rasmussen, P., Tordon, R., Dias, G., Kemp, J., Heyst, B. V., and 
Banic, C. M.: Gaseous mercury emissions from natural sources in Canadian landscapes, J. Geophys. Res., 110(D18), D18302, doi:10.1029/2004JD005699, 2005.

Valente, R., Shea, C., Humes, K., and Tanner, R.: Atmospheric mercury in the Great Smoky Mountains compared to regional and global levels, Atmos. Environ., 41, 1861-1873, 2007.
Walker, J. T., Robarge, W. P., Wu, Y., and Meyers, T. P.: Measurement of bi-directional ammonia fluxes over soybean using the modified Bowen-ratio technique, Agr. Forest Meteorol., 138, 54-68, 2006.

Webb, E. K., Pearman, G. I., and Leuning, R.: Correction of Flux Measurements for Density Effects Due to Heat and Water-Vapor Transfer, Q. J. Roy. Meteor. Soc., 106, 85-100, 1980. 